\title{
NORMAS PARA A PUBLICAÇÃO NA EM TESE NA LÍNGUA PORTUGUESA
}

Norms for publication of the academic journal Em Tese in Portuguese

\author{
Diego GREINERT \\ Doutorando em Sociologia e Ciência Política na \\ Universidade Federal de Santa Catarina \\ Editor-gerente da Revista Em Tese \\ diego_pnd@hotmail.com \\ https://orcid.org/0000-0002-0975-578X (i)
}

\author{
Ana Martina Baron ENGERROFF \\ Doutoranda em Sociologia e Ciência Política na \\ Universidade Federal de Santa Catarina \\ Editora-gerente da Revista Em Tese \\ anambaron@hotmail.com \\ https://orcid.org/0000-0002-3957-0428 (i) \\ Carolina Monteiro de Castro NASCIMENTO \\ Mestranda em Sociologia e Ciência Política na \\ Universidade Federal de Santa Catarina \\ Editora da Revista Em Tese \\ cah.castro@gmail.com \\ https://orcid.org/0000-0003-3227-2695
}

Mais informações da obra no final do artigo

\section{RESUMO}

Este texto objetiva trazer a síntese das normas da revista Em Tese, em conjunto com as normas da Biblioteca Universitária da Universidade Federal de Santa Catarina (UFSC). Aqui estão destacados exemplos de como adequar os artigos, resenhas, entrevistas e traduções às nossas normas, que estão disponibilizadas no site da revista e nos modelos dos templates acima citados. O resumo é um breve sumário do artigo. Ele deve ser uma descrição completa e sintética do conteúdo do artigo, que sintetize os propósitos, método e conclusões do trabalho. As informações devem ser expostas em um parágrafo, com narrativa contendo introdução (tema central do estudo e objetivos), meio (forma de abordagem do tema e fontes utilizadas) e fim (conclusões ou hipóteses principais). Instruções técnicas para elaboração do resumo: deve ser redigido em fonte Arial, tamanho 9, com espaçamento entre linhas do tipo simples, com alinhamento justificado e sem hifenização. Ele deve ser apresentado em parágrafo único e sem referências bibliográficas, contendo, até 10 linhas. Lembre-se, o resumo é uma vitrine para os leitores e é a partir dele que os pesquisadores tomam a decisão de lê-lo ou inclui-lo em suas investigações.

PALAVRAS-CHAVE: Utilize o campo palavras-chave para sintetizar sua pesquisa em 3 a 5 palavras-chave/keywords que identifiquem o conteúdo do artigo. Se outras pessoas tentassem encontrar seu estudo como elas buscariam? Evite mini frases e palavras compostas, exceto quando são significativas. As palavras-chave devem ser separadas entre si por ponto e finalizadas por ponto, conforme o exemplo abaixo:

Acessibilidade. Pesquisa. Qualidade.

\section{ABSTRACT \\ Incluir a tradução do resumo para a língua inglesa.}

KEYWORDS: Incluir a tradução das palavras-chave para a língua inglesa. 


\section{INTRODUÇÃO}

A Em Tese é uma Revista digital semestral do Programa de Pós-Graduação em Sociologia e Ciência Política (PPGSP) da Universidade Federal de Santa Catarina (UFSC). Seu escopo é a publicação de textos inéditos - artigos, ensaios, resenhas, entrevistas e traduções - de pós-graduandos (stricto sensu), mestres, doutores e pesquisadores da Sociologia, Ciência Política e áreas afins. Recebe textos no sistema de fluxo contínuo e dossiês temáticos.

Com o objetivo de ampliar o alcance da Em Tese, publicamos estas diretrizes traduzidas para a língua inglesa e espanhola. Neste template os autores e autoras poderão ter acesso às Diretrizes de publicação que estão contidas no site da revista, que estão de acordo com as normas da Associação Brasileira de Normas e Técnicas - ABNT (NBR 6023/2018), assim como os arquivos corretos para a postagem do seu texto.

A Em Tese utiliza como política da revista a avaliação "duplo-cego", na qual os pareceristas não têm o conhecimento dos nomes dos autores, assim como o contrário, visando garantir a lisura do processo de avaliação. Para isto, é necessário que os autores e autoras removam toda e qualquer informação que possa revelar a sua identificação.

A partir de maio de 2019, a Em Tese teve mudanças relacionadas à formatação $e$ ao modelo de estrutura de submissão dos artigos. Desta forma, disponibilizamos os modelos de artigos, resenhas e entrevistas para que os artigos sejam submetidos nesses arquivos. ${ }^{1}$ Da mesma forma, também disponibilizamos as "notas de autor". Neste documento serão inseridas todas as informações referentes aos autores, como nomes, titulação, local de trabalho, Orcid, entre outras. Todos os textos submetidos à avaliação na Em Tese deverão ter as "Notas de autor" preenchidas e submetidas como "documento suplementar", na própria página de submissão.

Os autores e as autoras deverão preencher todos os campos do seu cadastro na página da revista, incluindo o Orcid dos autores, informação que é obrigatória para a publicação dos artigos nesta revista.

Ainda neste modelo você terá acesso aos exemplos de como fazer citações diretas, indiretas, formatação e fonte, assim como realizar as referências bibliográficas de

\footnotetext{
${ }^{1}$ Ao clicar nos hiperlinks de "artigos", "resenhas" e "entrevistas", assim como as "notas de autor", você fará o download do template correto. Note que o template virá preenchido com uma série de informações que já estão inseridas neste modelo, visando auxiliar nas normas para o preenchimento e a publicação do texto.
} 
acordo com as normas da ABNT, auxiliando-o a submeter o texto seguindo todas as nossas diretrizes.

\section{NORMAS PARA PUBLICAÇÃO}

Estas normas visam auxiliar autores e autoras interessados em publicar na revista Em Tese, disponibilizando as versões em língua portuguesa, espanhola e inglesa, cujo objetivo é instigar a publicação não só de textos produzidos na língua materna desta Revista, como também a internacionalização da Em Tese com textos nestes outros idiomas.

Abaixo disponibilizamos várias informações contidas tanto nas diretrizes para autores quanto nos templates. O intuito de tê-las em um arquivo traduzido é o de incentivar publicações de pesquisadores de outros países. Além do mais, este arquivo busca sintetizar as normas, facilitando a leitura e trazendo exemplos de como e o quê deve ser preenchido nas versões submetidas aos autores e autoras. Confira a seguir quais são as normas para a publicação na Em Tese:

1. Todos os arquivos (artigo, entrevista, tradução e resenha) deverão estar de acordo com as normas da revista, assim como as notas de autoria (modelos disponibilizados na introdução deste texto), em formato .doc. A língua oficial da revista é o português, sendo aceitos também trabalhos nos idiomas espanhol e inglês.

2. Todos os manuscritos devem ser originais, inéditos e não devem estar sendo avaliados em outra revista. Qualquer informação divergente deve ser justificada no campo "Política de conflito de interesses". Excluir qualquer informação que possa revelar a autoria do trabalho.

3. O tamanho dos trabalhos deverá ser de no mínimo doze (12) páginas e no máximo vinte e cinco (25) páginas, excluindo-se as referências bibliográficas. O resumo deverá ser de até dez (10) linhas, assim como o abstract. Este deverá conter de três (3) a cinco (5) palavras-chave, no idioma do texto e no abstract.

4. Todas as fontes de financiamento devem ser divulgadas no documento "notas de autoria”, assim como todas as informações constantes neste documento, que deverá ser incluído no sistema por meio do campo "documento suplementar". 
5. A revista Em Tese aceita publicações de resenhas de livros recentemente publicados, cuja data de publicação não deve ultrapassar três (3) anos, com um mínimo de cinco (5) e o máximo de dez (10) páginas.

6. A revista Em Tese aceita a publicação de traduções de textos desde que acompanhada do original e da carta de autorização para tradução e republicação por parte do autor ou detentor dos direitos autorais.

7. A revista Em Tese aceita publicações de entrevistas desde que tenham relevância para a discussão acadêmica relacionada às Ciências Sociais e áreas afins, com no mínimo doze (12) páginas e no máximo vinte e cinco (25) páginas. Devem contar com um texto introdutório acerca do entrevistado, título no idioma original e inglês, e três palavras-chave nos dois idiomas.

8. Todas as entrevistas deverão ter uma carta de autorização por escrito do entrevistado, haja vista que a produção do documento é feita entre entrevistador e entrevistado e deve ser incluída no sistema por meio do campo "documento suplementar".

9. Cabe aos autores e autoras o cuidado com as imagens e os direitos autorais delas, assim como - em caso de direitos autorais - fazer o upload no sistema da autorização de utilização da(s) imagem(ns) por meio do campo "documento suplementar".

10. Todas as siglas deverão aparecer por extenso na sua primeira aparição no corpo do texto, excetuando-se nos títulos e subtítulos de seções.

11. Artigos submetidos à revista podem ter, no máximo, três autores. Resenhas submetidas à revista só podem ter um único autor.

12. É necessário que o autor da submissão, tanto para artigos quanto para resenhas, tenha a titulação de mestre. Graduandos podem submeter artigos em conjunto com um pesquisador que já tenha, no mínimo, o título de mestre.

13. É de inteira responsabilidade do autor a revisão das normas da ABNT (NBR 6023/2018) conforme a sua última atualização ocorrida em 14 de novembro de 2018, assim como a revisão ortográfica e gramática dos textos de acordo com a norma culta da língua portuguesa.

14. As submissões deverão estar de acordo com as normas da revista, caso contrário as mesmas poderão ser devolvidas aos autores para correções antes mesmo de ser encaminhada para o parecer.

15. Ao submeter o artigo para a Revista Em Tese (UFSC), deve ser cumprida a seguinte ordem de estruturação: 
- Título;

- Resumo na língua materna;

- Resumo na segunda língua;

- Conteúdo (introdução, desenvolvimento e conclusão, por exemplo);

- Referências bibliográficas; e

- Anexo, caso seja necessário.

O artigo deve usar o formato A4, com coluna simples, com no mínimo 12 e no máximo 25 páginas, não inclusa a lista de referências. Não alterar a paginação. Palavras estrangeiras devem estar em itálico.

$O$ tamanho das margens deve ser: inferior $3 \mathrm{~cm}$ - demais $2 \mathrm{~cm}$.

O título do artigo deve ser conciso, evitando excesso de palavras, em português e inglês, usando fonte Arial black, tamanho 16, cor preta, tudo em letras maiúsculas e em negrito. O título e subtítulo (se houver) devem ser separados por dois-pontos (:). Título: fonte Arial black, tamanho 16, cor preta, alinhado à esquerda sem hifenização. $O$ título em inglês usar fonte $10 \mathrm{e}$ em negrito.

O espaçamento do corpo do texto deve ser de 1,5 entre linhas; sem espaçamento entre parágrafos; com recuo de $1,25 \mathrm{~cm}$ no início de cada parágrafo.

A fonte do corpo do texto deve ser Arial, tamanho 12, com alinhamento justificado. Utilize o recurso estilo do Word para padronizar o texto, nesse template há alguns modelos criados conforme a característica do texto, ou seja, para citação com mais de três linhas, nota de rodapé, títulos, etc.

Exceto para as notas de rodapé ${ }^{2}$, utilize para a indicação da fonte (autoria) e conteúdo das figuras e tabelas, legendas, fonte Arial, tamanho 11.

As referências ao final do trabalho devem ser elaboradas com base na ABNT (NBR 6023/2018). A fonte das referências deve ser Arial, tamanho 12, com espaçamento simples entre linhas, com alinhamento à margem esquerda, sem recuo, com um espaçamento simples entre parágrafos e ordenadas alfabeticamente pelo sobrenome do autor.

\footnotetext{
${ }^{2}$ Exemplo de nota explicativa. Não utilizar para fazer referências bibliográficas, essas devem estar no item referências. Usar fonte tamanho 10 para o conteúdo das notas.
} 
Os títulos das seções e subseções devem usar fonte Arial, tamanho 12, em negrito, alinhados à margem esquerda, com espaçamento 1,5 entre linhas.

As siglas deverão ser utilizadas de forma padronizada, restringindo-se apenas àquelas usadas convencionalmente ou sancionadas pelo uso, acompanhadas do significado, por extenso, quando da primeira citação no texto.

\section{TÍTULO PRIMÁRIO}

Para o conteúdo das ilustrações, tabelas e quadros utilize fonte tamanho 11 em espaçamento simples.

Quadro 1 - Abreviaturas de alguns meses

\begin{tabular}{|l|l|l|l|}
\hline \multicolumn{2}{|c|}{ Português } & \multicolumn{2}{c|}{ Inglês } \\
\hline Janeiro & jan. & January & Jan. \\
\hline Fevereiro & fev. & February & Feb. \\
\hline Março & mar. & March & Mar. \\
\hline
\end{tabular}

Fonte: ABNT NBR-6023 (2003).

Tabela 1 - Modelo de tabela conforme normas IBGE

\begin{tabular}{lcccccc}
\hline \multirow{2}{*}{ ALIMENTO } & \multicolumn{5}{c}{ CONTEÚDO NUTRICIONAL } \\
\cline { 2 - 6 } & \multirow{2}{*}{$\begin{array}{c}\text { Cálcio } \\
(\mathrm{g})\end{array}$} & $\begin{array}{c}\text { Proteínas } \\
(\mathrm{g})\end{array}$ & $\begin{array}{c}\text { Lipídios } \\
(\mathrm{g})\end{array}$ & $\begin{array}{c}\text { Glicídios } \\
(\mathrm{g})\end{array}$ & $\begin{array}{c}\text { Cinzas } \\
(\mathrm{g})\end{array}$ \\
\hline (A) BATATA CRUA & 79,8 & 76 & 2,1 & 0,1 & 17,1 & 0,9 \\
(B) BATATA FRITA & 46,9 & 268 & 4,0 & 14,2 & 32,6 & 2,3 \\
\hline
\end{tabular}

Fonte: Instituto Brasileiro de Geografia e Estatística - IBGE (2018)

A tabela deve estar mais próxima possível do trecho a que se refere e ser mencionada, por exemplo: (Tabela 1), conforme Quadro 1. Deve ser centralizada na página.

\subsection{Título Secundário}

Somente as obras consultadas e citadas no texto do artigo devem compor a lista de referências. 


\subsubsection{Título Terciário}

Para as citações deve ser utilizado o formato autor/data com base na ABNT NBR 10520/2002. Não utilize o sistema de citação em nota de rodapé.

As citações diretas (literais) curtas, de até 3 (três) linhas, devem estar apresentadas entre aspas, no corpo do texto, sem destaque em itálico (ou qualquer outro destaque), seguidas da autoria entre parênteses (SOBRENOME do autor, ano, página (com espaço entre o ponto e o número da página). Exemplo: "Artigo científico é parte de uma publicação com autoria declarada, que apresenta e discute ideias, métodos, técnicas, processos e resultados nas diversas áreas do conhecimento." (ABNT, 2003, p. 2). Caso a identificação do autor seja feita no "corpo do texto", usa-se, por exemplo: Para Barros e Lehfeld (2000, p. 107), "as citações ou transcrições de documentos bibliográficos servem para fortalecer e apoiar a tese do pesquisador ou para documentar sua interpretação."

As citações diretas (literais) longas, com mais de 3 (três) linhas devem estar em parágrafo destacado do texto, com $4 \mathrm{~cm}$ de recuo à esquerda, alinhamento justificado, em espaço simples entre linhas, com espaçamento antes e depois 6, fonte Arial, tamanho 11, sem aspas, sem itálico (ou qualquer outro destaque), seguida da autoria entre parênteses: (SOBRENOME do autor, ano, página com espaço entre o ponto e o número), com ponto final depois dos parênteses.

Exemplo:

A língua, então, não é mais apenas o lugar onde os indivíduos se encontram; ela impõe também, a esse encontro, formas bem determinadas. Não é mais somente uma condição da vida social, mas um modo de vida social. Ela perde sua inocência. Deixar-se-á, portanto, de definir a língua, à moda de Saussure, como um código, isto é, como um instrumento de comunicação. Mas ela será considerada como um jogo, ou melhor, como o estabelecimento das regras de um jogo, e de um jogo que se confunde amplamente com a existência cotidiana (DUCROT, 1977, p. 12).

Já a citação indireta é uma paráfrase, elaborada a partir da ideia ou da opinião de um autor, em uma obra que foi consultada. Nesse caso, identifica-se somente o sobrenome do autor e o ano de publicação da obra, usando a mesma fonte do corpo do texto (fonte Arial, tamanho 12). Não é necessário colocar o número da página.

Exemplos: 
(a) No corpo do texto: somente a primeira letra do sobrenome do(s) autor(es) em maiúscula, com o ano entre parênteses; sem colocar o número de página.

- Na opinião de Souza e Faria (2000) [...].

- De maneira semelhante, Lopes (2008) [...].

(b) Ao final da citação: sobrenome do(s) autor(es) em letras maiúsculas.

... (SOUZA; FARIA, 2000).

... (LOPES, 2008).

A lista das referências exemplifica a indicação de livro, revista, legislação, anais, dados, entre outros, conforme a NBR 6023/2018.

Observação: é de inteira responsabilidade do autor a revisão das normas da ABNT (NBR 6023/2018) conforme a sua última atualização ocorrida em 14 de novembro de 2018, assim como a revisão ortográfica de acordo com a norma culta da língua portuguesa.

1. Os autores devem ser destacados no corpo do texto, em caixa alta, seguindo a seguinte orientação: (SOBRENOME DA/O AUTORA/OR, data) para citação indireta ou (SOBRENOME DA/O AUTORA/OR, data, página) para citação direta. Ex.: (REIS, 1989) ou (REIS, 1989, p. 64). Diferentes títulos da mesma autor publicados no mesmo ano serão identificados por uma letra após a data. Ex.: (DINIZ, 2003a), (DINIZ, 2003b). Quadros, mapas, tabelas etc. devem ser enviados no corpo do texto. Imagens e/ou figuras devem ser enviadas em formato “.jpeg”, resolução 300 dpi. A responsabilidade pelos direitos autorais de reprodução ficará a cargo do autor.

2. As referências bibliográficas utilizadas devem ser citadas ao final dos textos, listadas primeiro em ordem alfabética e em seguida por ordem numérica das publicações de um mesmo autor/a, obedecendo aos seguintes critérios:

Livro: SOBRENOME, Nome. Título em negrito, seguido de subtítulo (caso houver). Número da edição, caso não seja a primeira. Local da publicação: nome da editora, ano.

Capítulo em coletânea: SOBRENOME, Nome. Título do capítulo, In: SOBRENOME, Nome (abreviado ou não - seguir um padrão) do (s) organizador(es) (orgs.). Título da coletânea em negrito. Número da edição, caso não seja a primeira. Local da publicação: nome da editora, ano.

Artigo em periódico: SOBRENOME, Nome. Título do artigo. Nome do periódico em negrito, volume e número do periódico, intervalo de páginas do artigo, ano. 
Dissertacões e teses: SOBRENOME, Nome. Título da dissertação/tese em negrito. Dissertação (mestrado) ou Tese (doutorado) em [indicação da área do conhecimento]. Local: Instituição em que foi apresentada, ano.

Internet (documentos eletrônicos): SOBRENOME, Nome. Título. Nome da revista ou outra fonte em negrito. Disponível em: Indicação da URL. Acesso em: data de acesso, ano.

Legislação: LEGISLAÇÃO ou ENTIDADE, epígrafe ou ementa conforme a publicação em negrito, dados da publicação.

Ex: BRASIL. [Constituição (1988)]. Constituição da República Federativa do Brasil de 1988. Brasília, DF: Presidência da República, [2016]. Disponível em: http://www.planalto.gov.br/ccivil_03/Constituicao/ Constituiçao.htm. Acesso em: 1 jan. 2017.

Obs: de acordo com a atualização da ABNT (NBR 6023/2018), todos os arquivos retirados de meio eletrônico são obrigados a destacar o sistema "disponível em:/acesso em:".

\section{(Ex: https://periodicos.ufsc.br/index.php/emtese/article/view/1806-5023.2018v15n1p1.}

Acesso em: 14 dez. 2018). Não é requerido mais o hiperlink entre os sinais "<>". Outro indicativo é a opção pela utilização de encurtadores de hiperlinks, desde que haja padronização na lista de referências, sendo facultativo seu uso, mas obrigatória a padronização.

1. As submissões deverão estar de acordo com as normas da revista, caso contrário as mesmas poderão ser devolvidas aos autores para correções antes mesmo de ser encaminhada para o parecer.

2. Cabe exclusivamente aos autores a revisão ortográfica e gramatical dos textos enviados à revista Em Tese desde a sua primeira submissão.

\section{NOTAS}

TÍTULO DA OBRA

Normas para a publicação na Em Tese na Língua Portuguesa

Diego Greinert

Doutorando em Sociologia e Ciência Política na Universidade Federal de Santa Catarina

Editor-gerente da Revista Em Tese

diego_pnd@hotmail.com

Ohttps://orcid.org/0000-0002-0975-578X

\section{Ana Martina Baron Engerroff}

Doutoranda em Sociologia e Ciência Política na

Universidade Federal de Santa Catarina

Editora-gerente da Revista Em Tese 
anambaron@hotmail.com

\section{Ohttps://orcid.org/0000-0002-3957-0428}

\section{Carolina Monteiro de Castro Nascimento}

Mestranda em Sociologia e Ciência Política na

Universidade Federal de Santa Catarina

Editora da Revista Em Tese

cah.castro@gmail.com

Ohttps://orcid.org/0000-0003-3227-2695

\section{Endereço de correspondência do principal autor}

Não se aplica.

\section{AGRADECIMENTOS}

Não se aplica.

\section{FINANCIAMENTO}

Não se aplica.

\section{APROVAÇÃO DE COMITÊ DE ÉTICA EM PESQUISA \\ Não se aplica.}

\section{CONFLITO DE INTERESSES}

Não se aplica.

\section{LICENÇA DE USO}

Os autores cedem à Em Tese os direitos exclusivos de primeira publicação, com o trabalho simultaneamente licenciado sob a Licença Creative Commons Attribution 4.0 Internacional (CC BY). Estra licença permite que terceiros remixem, adaptem e criem a partir do trabalho publicado, atribuindo o devido crédito de autoria e publicação inicial neste periódico. Os autores têm autorização para assumir contratos adicionais separadamente, para distribuição não exclusiva da versão do trabalho publicada neste periódico (ex.: publicar em repositório institucional, em site pessoal, publicar uma tradução, ou como capítulo de livro), com reconhecimento de autoria e publicação inicial neste periódico.

\section{PUBLISHER}

Universidade Federal de Santa Catarina. Programa de Pós-Graduação em Sociologia e Ciência Política. Publicado no Portal de Periódicos UFSC. As ideias expressadas neste artigo são de responsabilidade de seus autores, não representando, necessariamente, a opinião dos editores ou da universidade. 